University of Nebraska - Lincoln

DigitalCommons@University of Nebraska - Lincoln

Faculty Publications: Department of

Entomology

Entomology, Department of

2007

Population Dynamics of Soybean Aphid and Biotic Mortality at the Edge of Its Range

Tierney R. Brosius

University of Nebraska-Lincoln

Leon G. Higley

University of Nebraska-Lincoln, Ihigley1@unl.edu

Thomas E. Hunt

University of Nebraska-Lincoln, thunt2@unl.edu

Follow this and additional works at: https://digitalcommons.unl.edu/entomologyfacpub

Part of the Entomology Commons

Brosius, Tierney R.; Higley, Leon G.; and Hunt, Thomas E., "Population Dynamics of Soybean Aphid and Biotic Mortality at the Edge of Its Range" (2007). Faculty Publications: Department of Entomology. 298. https://digitalcommons.unl.edu/entomologyfacpub/298

This Article is brought to you for free and open access by the Entomology, Department of at DigitalCommons@University of Nebraska - Lincoln. It has been accepted for inclusion in Faculty Publications: Department of Entomology by an authorized administrator of DigitalCommons@University of Nebraska - Lincoln. 


\title{
Population Dynamics of Soybean Aphid and Biotic Mortality at the Edge of Its Range
}

\author{
TIERNEY R. BROSIUS, L. G. HIGLEY, ${ }^{1}$ AND T. E. HUNT ${ }^{2}$ \\ Department of Entomology, University of Nebraska, 202 Plant Industry, Lincoln, NE 68583-0816
}

\begin{abstract}
J. Econ. Entomol. 100(4): 1268-1275 (2007)
ABSTRACT The soybean aphid, Aphis glycines Matsumura, was introduced to north central North America from Asia in 2000, and it has become a major pest of soybean, Glycine max (L.) Merr. Understanding how natural enemies impact aphid populations in the field is an important component in developing a comprehensive management plan. We examined the impact of naturally occurring predators in the field by using exclusion cages during July-August 2004 and 2005. Field cages of different mesh diameters were used to exclude different sizes of natural enemies from aphid-infested plots. Plots were surveyed twice weekly for A. glycines and natural enemies. Densities were recorded. Cage effects on mean temperature and soybean growth were found to be insignificant. Significant differences in aphid density were found between treatments in both years of the study (2004 and 2005); however, aphid densities between years were highly variable. Orius insidiosus (Say) was the most commonly occurring predator in the field. Other natural enemies were present in both years but not in high numbers. Parasitoids were present in both years, but their numbers did not suppress aphid densities. Treatment differences within years were related to the abundance of natural enemies. The large differences in aphid abundance between years were associated with the higher number of $O$. insidiosus found in the field in 2005 (416 total O. insidiosus) than in 2004 (149 total O. insidiosus). This study suggests that naturally occurring predators, primarily $O$. insidiosus, can have a large impact on A. glycines populations when predator populations are established before initial A. glycines colonization.
\end{abstract}

KEY WORDS Orius insidiosus, introduced pest, natural enemies

The soybean aphid, Aphis glycines Matsumura, was introduced to north central North America from Asia in 2000 , and it has rapidly moved across the Midwest, spreading to 21 U.S. states and three Canadian provinces (Venette and Ragsdale 2004). Throughout the new range of $A$. glycines, different native and introduced predators, different physical environments, and different climatic conditions occur. Consequently, it is important to understand how A. glycines interacts with these new ecosystems when developing effective management systems to manage this new pest.

The life history of the A. glycines is the same in North America as it is in Asia. In both North America and Asia, the primary overwintering host seems to be plants in the genus Rhamnus (Ragsdale et al. 2004). A. glycines switches plant hosts seasonally, and it is characterized as a heteroecious holocyclic species (hostalternating with sexual reproduction during part of its life cycle) (for details, see Ragsdale et al. 2004).

Abiotic and biotic factors have the potential to greatly influence aphid populations. Relatively little

\footnotetext{
${ }^{1}$ Corresponding author, e-mail: lhigleyl@unl.edu.

${ }^{2}$ Department of Entomology, Haskell Agricultural Laboratory, University of Nebraska, 57905866 Rd., Concord, NE 68728.
}

work has directly examined the influence of abiotic factors on A. glycines growth and mortality. A review of A. glycines populations, temperatures, and precipitation in the Jilin province of China over $10 \mathrm{yr}$ found that higher than mean temperatures $\left(22-23^{\circ} \mathrm{C}\right)$ and reduced rainfall $(<20 \mathrm{~mm})$ from 21 June to 10 July favored aphid development in comparison with other years with lower temperatures and higher mean rainfall amounts (Yue and Hao 1990). A study performed in North America under controlled conditions found that as temperature increased above the determined optimum temperature $\left(27.8^{\circ} \mathrm{C}\right)$ for $A$. glycines, net fecundity, gross fecundity, generation time, and life expectancy decreased (McCornack et al. 2004). Another factor that may determine the likelihood of an outbreak year is the number of viable overwintering eggs.

Greater research attention has been given to the influence of biotic factors on A. glycines, and natural enemies are thought to be the most significant biotic factor in regulating A. glycines populations. In their native habitat, A. glycines populations are found in lower densities than in the corresponding latitudes of North America (Fox et al. 2004). A. glycines is subject to many natural predators in their native Asia. In the 
Hunan province of China, populations of aphids were surveyed along with populations of natural predators. Aphid populations peaked at a mean of 188 per plant on 28 July, and then they decreased to a mean of 0.644 aphids per plant by 12 August (Han 1997). Predators soon followed the aphid population, peaking at 0.421 predators per plant on 2 August, $5 \mathrm{~d}$ after the aphids peaked. By 17 August, the predator numbers dropped to 0.135 predators per plant. The ratios of aphids to natural enemies decreased from 310.2 aphids per predator to 10.4 aphids per predator (Han 1997). This study suggests that natural enemies are effective in China; yet, little is known about natural control of A. glycines in the United States.

An Indonesian study showed an association between peak A. glycines densities and peak coccinellid densities at individual sites (van den Berg et al. 1997). Peak aphid density explained $28 \%$ of the variance in peak coccinellid densities. Coccinellid larvae (Harmonia spp.) were found feeding on aphids, and when the aphids were at high densities, $88 \%$ of the aphids eaten were in early instars. Coccinellid larvae consumed aphids at a rate of 120 aphids per day when aphids were at these high densities. In this tropical ecosystem, the authors concluded that aphid densities on young soybean, Glycine max (L.) Merr., plants $(<40 \mathrm{~d}$ old $)$ were relatively unaffected by predators (because predator populations did not reach sufficiently high densities), but aphid population declines on older soybean plants were attributed to predation (where predator densities were much greater) (van den Berg et al. 1997).

Several predators have been reported to feed on A. glycines in the United States. Damsel bugs (Nabis spp.), aphid flies (chamaemyiid larvae), ladybugs (coccinellid species), and minute pirate bugs (Orius spp.) have all been reported as some of the most abundant predators occurring in soybean fields (Fox et al. 2004, Rutledge et al. 2004). In one study, $85 \%$ of the predators feeding on A. glycines in the field were Orius insidiosus (Say) and the coccinellid Harmonia axyridis Pallas. Ground-dwelling predators ate fewer aphids than foliar-foraging predators (Rutledge et al. 2004), probably because A. glyciness do not drop off the plant when disturbed as do many other aphids (Losey and Denno 1998).

In Michigan, a series of cage studies were used to evaluate the impact of A. glycines predators in the field (Fox et al. 2004). Aphid populations were strongly affected by the caged treatments. Cages seemed to prevent foliar-feeding predators from feeding on the aphids. In those treatments without cages, aphid densities were $\approx 10$ aphids per plant, whereas predatorexcluded cages had a mean of 200 aphids per plant. This study provided strong evidence that existing generalist predator communities may be capable of suppressing A. glycines populations below economic injury levels (EILs). Another Michigan cage study illustrated that exclusion cages effectively protected aphid populations from large predators (primarily Coccinellidae), but they did not find a significant impact of small generalist predators on aphid populations (Costamagna and Landis 2006).

In Iowa, populations of $A$. glycines reached $>2,000$ per plant in 2001 and in 2003; however, in 2002 and 2004 , populations were $<250$ per plant (Rice et al. 2005). Areas throughout the new range of A. glycines have had "outbreak years" when aphids were at numbers at or above the EILs, as well as years when aphids were not an economic problem. Possible explanations for the occurrence of aphid outbreaks include differences in overwintering survival, phenological differences in aphid movement to soybean, temperature, rainfall, or changes in natural enemy populations across years; but, as yet, there is not sufficient research evidence to support any single or multiple causes of outbreaks.

Nebraska is located on the western edge of the range of A. glycines. Since their first appearance in Nebraska in 2002, A. glycines populations in Nebraska have not occurred as early in the season, and they have been more variable than those in states to the east (Ostlie 2001, Hunt 2004, Rice et al. 2005). Given that Nebraska is at the western limit of the North American range of A. glycines and that observations of the population phenology and densities of this aphid in Nebraska are different from those of more easterly states (including differences from immediately adjacent states), understanding factors influencing $A$. glycines population biology is of great interest. In particular, the interplay of A. glycines biology, the abiotic environment, and natural enemies in areas of Nebraska where large A. glycines outbreaks have not occurred may lead to insight into conditions associated with the occurrence of outbreaks elsewhere in the range of $A$. glycines. Consequently, the objective of this study was to examine A. glycines population dynamics experimentally in Nebraska, with manipulations of natural enemies to determine the importance of specific biotic factors on population change.

\section{Materials and Methods}

Field Site. Experiments were conducted at the University of Nebraska Haskell Agricultural Laboratory, Concord, NE. Research plots were located in soybean fields under a 2-yr corn (Zea mays L.) -soybean rotation with conventional tillage practices (2004 Colo silty clay loam, $0-2 \%$ slope and in 2005 Baltic silty clay, 0\% slope). On 29 May 2004 and 23 May 2005, after double disking for seed bed preparation, fields were planted with soybean (Asgrow 2730) at 176,000 seeds per ha in 0.762-m rows. Experiments were conducted in these fields in individual plots, which were located at least $5 \mathrm{~m}$ from field borders to minimize any edge effects. Glyphosate at 1.14 liter formulation per 0.4 ha was applied twice each year. Applications were made on 9 June and 28 June 2004 and on 27 May and 24 June 2005. Different fields were used each year of the study, but they were within proximity to one another $(<1 \mathrm{~km})$.

Study Design. The experimental design was a randomized complete block, with treatments located in 
Table 1. Dates for experimental operations in each year of the study, including establishing cages, pretreatment application of malathion to remove any natural enemies before infestation, $A$. glycines inoculation of plots (=plots infested), and sampling dates (when $A$. glycines and natural enemies were counted, and plants staged) (see Materials and Methods for additional details)

\begin{tabular}{ccccc}
\hline \hline Yr & $\begin{array}{c}\text { Cages over } \\
\text { plots }\end{array}$ & $\begin{array}{c}\text { Insecticide } \\
\text { application }\end{array}$ & $\begin{array}{c}\text { Plots } \\
\text { infested }\end{array}$ & Sampling dates \\
\hline 2004 & 19 July & 23 July & 26 July & $\begin{array}{c}5,9,11,13,16,20, \\
25,27,29 \text { Aug. }\end{array}$ \\
& & & 18,16 Sept. \\
2005 & July & 22 July & 28 July & $\begin{array}{l}\text { 5, 9, 16, 18, 21, 25, } \\
\text { 20 Aug. }\end{array}$ \\
& & & $1,6,8,15$ Sept. \\
\hline
\end{tabular}

cages with different sized mesh coverings or uncaged soybean of equal dimensions as cages (for the uncaged control treatment). Each cage represented one experimental unit, and there were four blocks of four treatments for a total of 16 experimental units. The cage covered 1.8- by 3.7-m ground area (centered over two rows), and cage supports (2.5-cm-diameter aluminum poles) were $2 \mathrm{~m}$ in height and extended into the ground $0.5 \mathrm{~m}$.

Custom field cages were placed over the aluminum supports, and they consisted of nylon mesh of 1 or 2 $\mathrm{mm}$ squares and a full-length zipper opening on one side. Specific treatments were 1) control: no cage, staked 1.8- by 3.7-m ground area; 2) control: cage, 2 -mm mesh rolled up to allow complete access to canopy by all types of natural enemies; 3) partial exclusion cage: 2 -mm mesh, intended to exclude large natural enemies (primary predators); and 4) total exclusion cage: 1 -mm mesh, intended to exclude all natural enemies, and if natural enemies were found these were manually removed.

In 2004, temperatures were recorded at ground level, mid-canopy, and immediately above the canopy with thermocouples (TMC6- $\mathrm{HB}, 0-44^{\circ} \mathrm{C}$ range, $\pm 0.4^{\circ} \mathrm{C}$ accuracy at $20^{\circ} \mathrm{C}$, and $0.2^{\circ} \mathrm{C}$ resolution) attached to a Hobo H8 Outdoor/Industrial 4-Channel External Logger (Onset Computer Corp., Pocasset, MA). Data were recorded from four replications; however, one thermocouple failed in one replication of the caged control treatment. Measurements were recorded at hourly intervals. For general environmental conditions (temperatures, relative humidity, and rainfall) at the experimental site, data from an automatic weather station on the Haskell Agricultural Laboratory (within $2 \mathrm{~km}$ of the experimental site) were used. Environmental data were determined from the beginning to end of the experimental period (when cages were placed on plots) in each year.

Dates of all activities involving treatment establishment and assessment are listed in Table 1. Exclusion treatments (those with 1- or 2-mm mesh cages) were treated to remove preexisting predators with the 0.052 liters (AI) / ha of malathion (which has a short half-life of 1.5 d in sunlight; EPA 1991). One week later, aphid treatments were artificially infested with healthy adult apterous aphids from a nearby field at three adult aphids per plant to simulate initial infestation ob-
Table 2. Total natural enemies recorded across all sampling dates in 2004 and 2005 , by taxon

\begin{tabular}{lrr}
\hline \hline \multicolumn{1}{c}{ Natural enemy } & 2004 & 2005 \\
\hline Chrysopid adult & 18 & 0 \\
Chrysopid larvae & 44 & 2 \\
Chrysopid eggs & 41 & 24 \\
O. insidiosus & 149 & 416 \\
Syrphid larvae & 74 & 2 \\
H. axyridis adult & 7 & 0 \\
Coccinelid larvae & 33 & 0 \\
Coccinelid eggs & 1 & 0 \\
Parasitoid mummies & 794 & 17 \\
Nabid nymphs and adults & 0 & 4 \\
Total of all types & 1,161 & 465 \\
\hline
\end{tabular}

served locally. Natural aphid infestations were similar, but variable by field, in both years.

Aphid and natural enemy counts were made two to three times weekly (until soybean plants senesced; Table 1) on six plants chosen at random within each plot (in 2004, only four plants were sampled after 11 August). Counts included nymphal, adult apterous, and adult pterous aphids and natural enemies identified to the lowest possible taxon at the time of field counts (Table 2). Aphid number and natural enemy type and number were recorded for individual leaves starting from the base of the plant. Each leaf was designated by counting the nodes from the base of the plant in the same method used to determine the vegetative stage of the plant. Aphids were counted individually until their numbers became too large $(>100$ per leaf), and then they were counted by tens or hundreds. Accuracy of counts by tens or hundreds was tested on each sampling date by directly comparing individual counts and estimates on at least one leaf in each plot (16 total), until estimates were within $10 \%$ of individual counts. Additionally, the same individual (T.R.B.) counted at all times to avoid potential error among samplers. The vegetative and reproductive stage (Ritchie et al. 1995) of the soybean plants also were recorded on each sampling date.

Data Analysis. Our a priori treatment comparisons of interest were 1) control: no cage versus control: cage, to identify potential cage effects; and 2) to compare no control: cage (all natural enemies), exclusion cage: $2 \mathrm{~mm}$ (no large predators, principally parasitoids and minute pirate bugs), and exclusion cage: $1 \mathrm{~mm}$ (no natural enemies). Data were analyzed by analysis of variance (ANOVA) through PROC MIXED, SAS 9.1 (SAS Institute 2002). Treatments were compared at the 0.05 level of significance, unless otherwise indicated.

Response variables included the means by date and across all dates: mean adult aphids, natural enemies, and plant stages. Correlations between aphids and specific natural enemies were determined by PROC CORR and PROC GLM procedures, SAS 9.1 (SAS Institute 2002). For analysis across dates, a repeated measures analysis was conducted with PROC MIXED, by using sampling date as the whole plot. Because appropriate use of PROC MIXED for repeated measures analysis requires estimation of the covariance 
Table 3. Daily mean temperatures $\left({ }^{\circ} \mathrm{C}\right)$ recorded by treatment in 2004 to identify any potential treatment $(=c a g e$ and mesh combination) effects (with standard error in parentheses after the mean)

\begin{tabular}{llcr}
\hline \hline \multicolumn{1}{c}{ Treatment } & $\begin{array}{c}\text { Bottom } \\
\text { canopy }\end{array}$ & $\begin{array}{c}\text { Middle } \\
\text { canopy }\end{array}$ & Top canopy \\
\hline Total exclusion & $17.80(0.14)$ & $17.92(0.15)$ & $17.99(0.15)$ \\
Partial exclusion & $17.77(0.13)$ & $17.93(0.14)$ & $18.13(0.16)$ \\
Caged control & $17.80(0.12)$ & $17.96(0.12)$ & $18.09(0.18)$ \\
Uncaged control & $17.75(0.13)$ & $17.95(0.15)$ & $18.21(0.17)$ \\
Canopy means & $17.78 \mathrm{a}(0.07)$ & $17.94 \mathrm{ab}(0.07)$ & $18.11 \mathrm{~b}(0.08)$ \\
\hline
\end{tabular}

Temperature data from thermocouple placed in bottom canopy (within $3 \mathrm{~cm}$ of ground), middle canopy (middle of soybean canopy), or top (within $3 \mathrm{~cm}$ above canopy). Letters after means indicate significant differences at the 0.01 level by analysis of variance and protected paired $t$-tests: for treatment comparisons, letters apply in the treatment means column; for canopy levels comparisons, letters apply across the canopy means row.

structure (variance components), we iteratively tested different covariance structures to identify the structure with the lowest fit statistics (Akaike's Information Criterion [AIC]). The lowest AIC was achieved with an antedependent structure, which we used in subsequent repeated measures analysis under PROC MIXED (Littell et al. 1996).

\section{Results and Discussion}

Cage Effects. No significant cage effect on aphid density was observed in either year (Table 4). As expected, temperatures did significantly differ between canopy strata $\left(F_{2,17}=30.45 ; P>F<0.0001\right)$; however, no significant difference were observed among temperatures, nor was there a significant stratum by temperature interaction (Table 3). Fox et al. (2004) also found that their cages had little influence on temperature or humidity.

We found no significant treatment differences in soybean reproductive stages (2004: $F_{3,9}=0.15, P>$ $\left.F=0.9263 ; 2005: F_{3,9}=2.30, P>F=0.1455\right)$ or vegetative stages (2004: $F_{3,9}=1.66, P>F=0.2436$; 2005: $\left.F_{3,9}=2.64, P>F=0.1130\right)$. Rutledge and O'Neil (2006) argued that the effect of soybean plant stage on A. glycines populations is not significant. This evidence along with the lack of significant differences in cage temperatures or in the number of aphids in the caged and open controls indicates that cages did not of themselves alter aphid numbers. Because no significant differences were found in the number of aphids and predators for both years of the study, the uncaged control treatment is omitted from the results.

Abiotic Effects. Across all treatments, mean aphid densities were lower in 2005 and than 2004 (Table 4), so potential abiotic effects between years merit examination. Mean daily high temperatures during the studies differed by $2.03^{\circ} \mathrm{C}$ between years $\left(26.73^{\circ} \mathrm{C}\right.$ in 2004 versus $28.76^{\circ} \mathrm{C}$ in 2005$)$. Other studies indicate that A. glycines perform better under mild temperatures (McCornack et al. 2004), so higher temperatures in 2005 might be thought to reduce aphid densities through impeding successful colonization. Humidity and rainfall were slightly higher in 2005 than in 2004 ( $56 \% \mathrm{RH}$ and $5.5 \mathrm{~cm}$ of total rainfall in 2004 versus $72 \%$ $\mathrm{RH}$ and $9.6 \mathrm{~cm}$ of total rainfall in 2005), but we saw no evidence that higher humidity or rainfall in 2005 directly contributed to greater aphid mortality. In particular, we saw no evidence of diseased aphids in 2005.

Evidence that biotic, not abiotic, factors most significantly influenced aphid numbers between years was provided by comparing aphid densities in total exclusion cages (which excluded natural enemies) (Table 4). Aphid densities totaled across all sampling dates in total exclusion treatments were 973.3 in 2004 and 818.2 in 2005 , and they were not significantly different by least significant difference (LSD) test.

Aphid Population Dynamics. In 2004, aphid numbers increased in all plots until the beginning of September when the populations began to decline (Fig. $1)$. The 2004 treatment, effects were significant $\left(F_{3,9}=\right.$ 11.14; $P>F=0.0022)$. The highest mean number of

Table 4. Mean total numbers of $A$. glycines per plant and natural enemies per plant (accumulated across sampling dates) by year, by treatment, and across all treatments

\begin{tabular}{|c|c|c|c|c|}
\hline & \multicolumn{4}{|c|}{ Mean no. per plant } \\
\hline & $\begin{array}{c}\text { Total } \\
\text { exclusion }\end{array}$ & $\begin{array}{c}\text { Partial } \\
\text { exclusion }\end{array}$ & $\begin{array}{c}\text { Uncaged } \\
\text { control }\end{array}$ & All \\
\hline \multicolumn{5}{|l|}{2004} \\
\hline A. glycines & $973.31(98.71)$ & $925.97(105.75)$ & $523.57(56.50)$ & $807.99(52.36)$ \\
\hline All predators & $0.04(0.01)$ & $0.8(0.40)$ & $0.79(0.29)$ & $0.54(0.16)$ \\
\hline All parasitoids & $0.85(0.23)$ & $2.25(0.49)$ & $0.28(0.07)$ & $1.13(0.19)$ \\
\hline O. insidiosus & $0.01(0.01)$ & $0.18(0.03)$ & $0.36(0.5)$ & $0.18(0.02)$ \\
\hline \multicolumn{5}{|l|}{2005} \\
\hline A. glycines & $818.17(75.20)$ & $22.86(2.80)$ & $7.17(0.65)$ & $282.74(28.76)$ \\
\hline All predators & $0.04(0.02)$ & $0.03(0.01)$ & $0.12(0.03)$ & $0.06(0.01)$ \\
\hline All parasitoids & $0(0.00)$ & $0.05(0.02)$ & $0(0.00)$ & $0.02(0.01)$ \\
\hline O. insidiosus & $0.20(0.04)$ & $0.56(0.07)$ & $0.47(0.06)$ & $0.41(0.03)$ \\
\hline
\end{tabular}




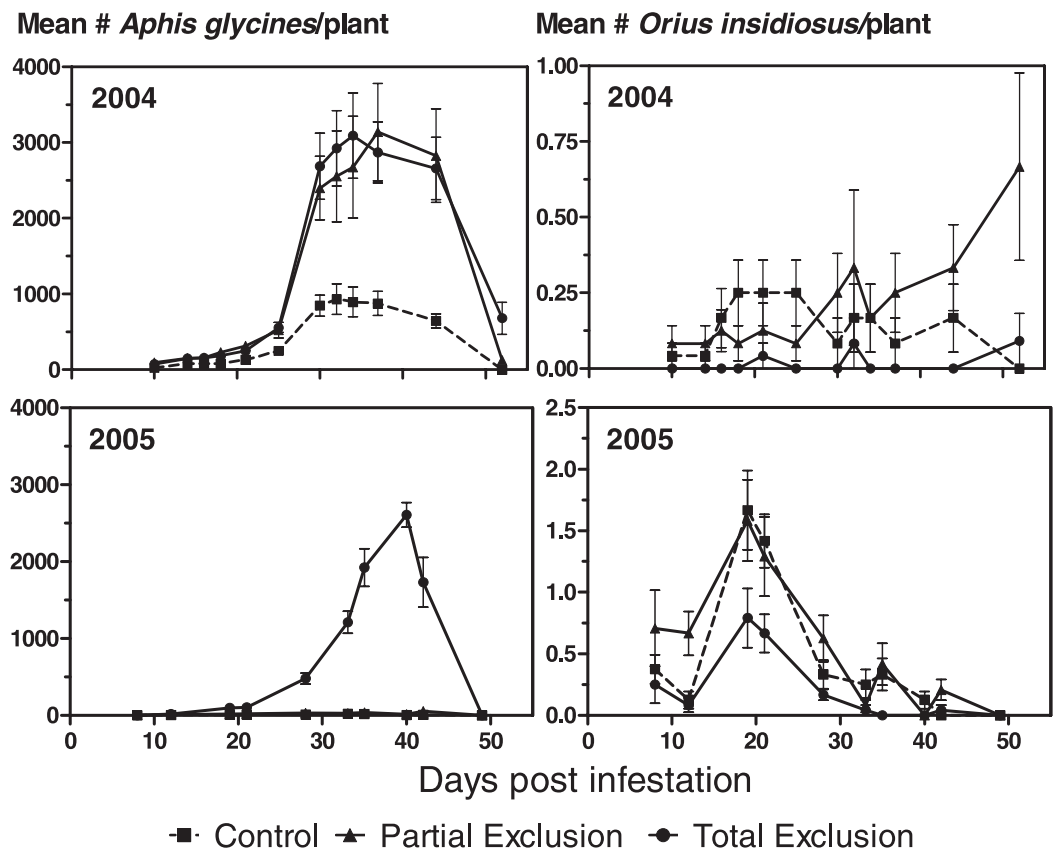

Fig. 1. Mean numbers of A. glycines per plant and O. insidiosus per plant in 2004 and 2005. In 2004, surveys began on 5 August and ended on 16 September; in 2005, surveys began 5 August and ended on 15 September.

aphids per plant was found in the total exclusion treatments $(3,091)$, then the partial exclusion treatments $(2,826)$, and finally the no exclusion treatment, which had the lowest aphid mean (932) (Fig. 1). These results corresponded with the natural enemies found in each treatment (Table 4). The total exclusion treatment had very few predators, and those that were counted were removed. The partial exclusion treatment had small natural enemies, primarily $O$. insidiosus, and parasitoids. In 2005, aphid numbers increased in all plots until the beginning of September when the populations began to decline (Fig. 1). The 2005 treatment effects were significant $\left(F_{3,9}=181.65 ; P>F=\right.$ 0.0001 ); specifically, the total exclusion treatment was significantly different $\left(\mathrm{LSD}_{0.05}=95.56\right)$ from other treatments. The number of aphids found in the total exclusion treatment was dramatically higher than the number found in both the no exclusion and the partial exclusion treatment (Fig. 1). The numbers found in the no exclusion and partial exclusion treatments were much lower in 2005 than in any of the treatments in 2004.

A likely explanation for differences in aphid densities seen between the $2 \mathrm{yr}$ of the study was in the number and type of predators seen in the field (Table 4). Observed differences in predators are associated with population fluctuations between treatments and between years in this study. In other work, Ragsdale et al. (2004) reported that "Although aphid populations can drop precipitously during fungal epizootics and occasionally parasitism rates can be locally high, predators remain the most significant natural enemy in Midwestern soybean fields."
The most significant natural enemy in our study seemed to be $O$. insidiosus. Large differences in aphid abundance between years were associated with the higher number of $O$. insidiosus found in the field in 2005 (416 total $O$. insidiosus) than in 2004 (149 total $O$. insidiosus). Results in 2005 show that the mean number of aphids per plant in the total exclusion cages (fine mesh) was significantly different than the number of aphids found in the other treatments $\left(\mathrm{LSD}_{0.05}=\right.$ 95.567). The total exclusion cage had a maximum of 2,600 aphids per plant. The partial exclusion treatment had a maximum population of around 50 aphids per plant, whereas the complete exposure treatment had a maximum of just $>10$ aphids per plant. This difference corresponds with the mean number of $O$. insidiosus per plant (Table 4). There was no significant difference in the mean number of $O$. insidiosus between the total exposure and partial exclusion treatments $\left(\mathrm{LSD}_{0.05}=0.33\right)$, showing that $O$. insidiosus could pass through the coarse mesh netting used for the partial exclusion. $O$. insidiosus numbers in total exclusion treatments were significantly lower than numbers found in the other two treatments $\left(\mathrm{LSD}_{0.05}=\right.$ $0.33)$.

O. insidiosus is a generalist predator within soybean. For example, $O$. insidiosus made up 55\% of the total predators collected in Missouri soybean fields (Barry 1973). This predator is attracted to beans during the crops reproductive stages where they feed on thrips and leafhopper nymphs (Ignoffo et al. 1976, Isenhour and Marston 1981). In corn, O. insidiosus populations are thought to be tied to silking and pollen shed, because populations of $O$. insidiosus attained their 


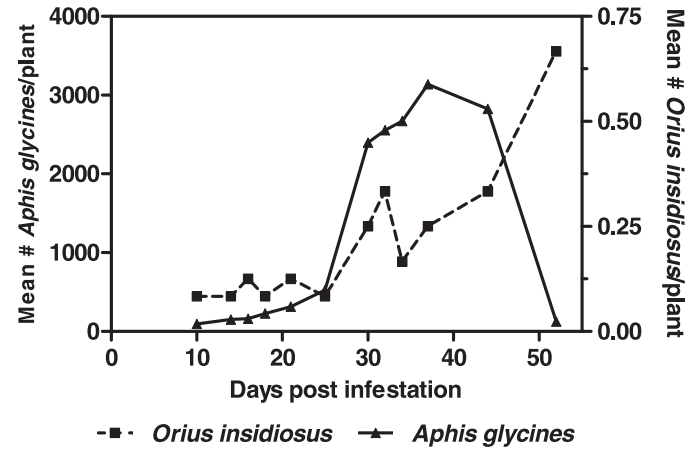

Fig. 2. Mean aphid per plant densities in relation to mean $O$. insidiosus per plant densities in the partial exclusion treatment. In 2004, surveys began on 5 August and ended on 16 September; in 2005, surveys began 5 August and ended on 15 September.

seasonal peak during these reproductive phases of corn development (Isenhour et al. 1981). O. insidiosus has become one of the main predators of A. glycines since the introduction of this aphid. Rutledge et al. (2004) observed that $O$. insidiosus may prevent population growth in low numbers of aphids $(12,24$, and 48 per plant), but when aphid populations reach a higher number (64 per plant), there is no significant difference between the replicates with and without the presence of $O$. insidiosus.

Data from this study support observations by Rutledge et al. (2004)). In 2005, O. insidiosus numbers grew to [more] 1.5 per plant in the field during the first $20 \mathrm{~d}$ of infestation in both the control and coarse mesh treatments (Fig. 2). The total exclusion treatment only reached $0.67 \mathrm{O}$. insidiosus per plant. In those treatments with high numbers of $O$. insidiosus, mean aphid numbers never grew $>40$ aphids per plant, far below the currently recommended economic threshold (ET) of 250 aphids per plant (Hunt 2004). In 2004, initial $O$. insidiosus densities were not sufficiently large enough to suppress aphid population growth. The lack of $O$. insidiosus at the start of the study may explain the sudden increase of aphid numbers in the partial exclusion (reaching a mean of $>3,000$ per plant) (Fig. 2). Even the aphid numbers in the control surpassed the traditional ET, reaching a mean of 933 aphids per plant. In 2004, O. insidiosus numbers in the partial exclusion treatments seem to track with aphid numbers in the last days of the study; however, there is no evidence that $O$. insidiosus was able to provide any control of the aphid (Fig. 2).

The differences in aphid abundance between years could be caused by the differences in initial densities of $O$. insidiosus present in the field. The populations of $O$. insidiosus are usually linked to prey abundance (Isenhour and Marston 1981). A mean of 0.75 O. insidiosus per plant was recorded at the start of 2005 versus $0.08 \mathrm{O}$. insidiosus per plant recorded at the start of 2004. In 2005, O. insidiosus where abundant and may have been able to prevent the successful colonization of aphids within treatments. The total exclusion treat- ment reduced $O$. insidiosus populations sufficiently to let aphid populations rapidly increase. Aphid populations did not begin to build in the total exclusion plots until day 19 of the study, and, by this time, the number of $O$. insidiosus had dropped in the total exclusion treatment from 0.67 to $<0.25$ per plant, again pointing to the evidence that there were not enough $O$. insidiosus present to suppress aphid numbers. The ability to suppress aphid growth when colony sizes are low suggests that $O$. insidiosus may be able to exert pressure on colonizing aphids, preventing them from increasing in population (Rutledge et al. 2004). In 2001 10 fields in central and northern Indiana were sampled weekly for aphids and $O$. insidiosus. This study showed a significant negative relationship between the length of time $O$. insidiosus was present in the field before the colonization of aphids and the number of aphids (Rutledge et al. 2004).

Higher temperatures did not suppress the population growth of the aphids in the total exclusion cage in 2005 , but we cannot disregard the potential interaction between natural enemies and temperatures in preventing successful aphid colonization. $O$. insidiosus may have worked in conjunction with the higher temperatures in 2005 to prevent $A$. glycines colonization.

Somewhat surprisingly, no coccinellids were observed on treatments in 2005. However, aphid populations, and subsequently $H$. axyridis, were at very low densities throughout Nebraska in 2005. Although coccinellids were observed in the field occasionally in 2004 , none were recorded within the plots until day 32 of the study. By this time, aphid numbers had built up to the ET in all treatments. The control reported the highest mean at 0.75 coccinellids per plant. We did observe coccinellids in 2004 and 2005 in areas outside of the experimental plots, and we have seen coccinellids in other soybean fields in northeastern Nebraska in association with A. glycines. However, aphid and coccinelid densities were variable in 2004 , so the scarcity of coccinellids in our experimental plots does not seem to be atypical of conditions in northeastern $\mathrm{Ne}$ braska.

Parasitoids were not found to substantially reduce aphid numbers, mostly because parasitoids occurred after aphid densities were already above EILs. In support of this interpretation, the Pearson correlation coefficient (run across years for this study) between parasitoids and aphid numbers found a significant positive correlation $(P=0.63 P>r=0.0001)$, suggesting parasitoids tracking but not affecting aphid numbers. When a correlation was run across years, $O$. insidiosus was the only factor to show a significant negative correlation with aphid numbers $(P=-0.64 ; P>r=$ 0.0001 ). This is strong evidence for $O$. insidiosus being one of the most efficient aphid predators in Nebraska soybean fields.

Nebraska soybean are not colonized by aphids until mid- to late July, unlike states to the east where colonization is seen as early as the beginning of June. This delay in colonization suggests that aphid overwintering success is limited. The likely explanation for the late colonization in Nebraska is that the aphids are 
migrating from states further east where buckthorn, Rhamnus cathartica L., stands are more common. This late colonization could be of great benefit to Nebraska farmers. Early infestation and treatment can result in the extermination of natural enemies, leading to a resurgence in aphid numbers. Later infestations may need only one treatment to suppress aphid numbers.

This study clearly shows that natural enemies are an important component of A. glycines management, but not all enemies are equal in there effectiveness in preventing aphid outbreaks or decreasing aphid abundance. In the system studied, O. insidiosus were found to be the most influential predators when large populations were present at the start of the aphid infestation.

Given the scale of this study, we cannot conclude that $O$. insidiosus is the only significant natural enemy of A. glycines in northeastern Nebraska or that in some areas or circumstances other natural enemies may not be significant. However, the ecologies of many pests and their natural enemies become significantly different as the edges of their ranges were approached (Godfrey et al. 1991, Barrigossi et al. 2001).

In particular, we expect the population dynamics of any species to be more variable at the edge of its range, given that the range limit reflects limitations in species requisites (when the range is not limited by a physical, geographical barrier) (Andrewartha and Birch 1984). Variation in pest dynamics necessarily influences natural enemy population dynamics and the ability of natural enemies to influence pest numbers. From this perspective, we might anticipate the action of natural enemies on A. glycines to be more significant and more predictable away from the edges of $A$. glycines range, and research to date generally supports this expectation (Fox et al. 2004, Costamanga and Landis 2006, Costamagna et al. 2007). Consequently, results here are sufficiently different from those reported farther east to imply that key factors influencing A. glycines at the western edge of its range are different from those elsewhere.

\section{Acknowledgments}

We thank Gerald Echtenkamp and Stephen Spomer for assistance with experiments and Erin Blankenship for statistical advice. This work was supported by the Nebraska Agricultural Experiment Station Projects NEB-17-078 and NEB-17-080) and by two grants from the Nebraska Soybean Board

\section{References Cited}

Andrewartha, H. G., and L. C. Birch. 1984. The Ecological Web. The University of Chicago Press, Chicago, IL.

Barrigossi, J.A.F., G. L. Hein, and L. G. Higley. 2001. Life tables and larval dispersal of Mexican bean beetle (Coleoptera: Coccinellidae) on dry bean in the high plains. Environ. Entomol 30: 235-243.

Barry, R. M. 1973. A note on the species composition of predators in Missouri soybeans. J. Ga. Entomol. Soc. 8: 284-286.
Costamagna, A. C., and D. A. Landis. 2006. Predators exert top-down control of soybean aphid across a gradient of agricultural management systems. Ecol. Appl. 16: 16191628.

Costamagna, A. C., D. A. Landis, and C. D. DiFonzo. 2007. Suppression of soybean aphid by generalist predators results in a trophic cascade in soybeans. Ecol. Appl. (in press).

Fox, T. B., D. A. Landis, F. F. Cardoso, and C. D. DiFonzo. 2004. Predators suppress Aphis glycines Matsumura population growth in soybean. Environ. Entomol. 33: 608618.

Godfrey, L. D., K. E. Godfrey, T. E. Hunt, and S. M. Spomer. 1991. Natural enemies of European corn borer Ostrinia nubilalis (Hubner) (Lepidoptera: Pyralidae) larvae in irrigated and drought-stressed corn. J. Kans. Entomol. Soc. 64: 279-286.

Han, X. 1997. Population dynamics of soybean aphid Aphis glycines and its natural enemies in fields. Hubei Agric. Sci. 2: $22-24$.

Hunt, T. E. 2004. Soybean aphid management. NF 599. Cooperative Extension Service, Institute of Agriculture and Natural Resources, University of Nebraska-Lincoln, Lincoln, NE.

Ignoffo, C. M., N. L. Marston, B. Puttler, D. L. Hostetter, G. D. Thomas, K. D. Biever, and W. A. Dickerson. 1976. Natural biotic agents controlling insect pests in Missouri soybeans, pp. 561-578. In L. D. Hill [ed.], World soybean research. Interstate Printers and Publishers, Inc., Danville, IL.

Isenhour, D. J., and N. L. Marston. 1981. Seasonal cycles of Orius insidiosus (Hemiptera: Anthocoridae) in Missouri soybeans. J. Kans. Entomol. Soc. 54: 129-142.

Littell, R. C., G. A. Milliken, W. W. Stroup, and R. D. Wolfinger. 1996. SAS systems for mixed models. SAS Institute, Cary, NC.

Losey, J. C., and R. F. Denno. 1998. The escape response of pea aphids to foliar-feeding predators: factors affecting dropping behavior. Ecol. Entomol. 23: 53-61.

McCornack, B. P., D. W. Ragsdale, and R. C. Venette. 2004. Demography of soybean aphid (Homoptera: Aphididae) at summer temperatures. J. Econ. Entomol. 97: 857-861.

Ostlie, K. 2001. A. glycines reduces yields: harvest results from insecticide strip trials. University of Minnesota, St. Paul, MN. (www.soybeans.umn.edu.crop/insects/aphid/ studyresults.htm).

Ragsdale, D. W., D. J. Voegtlin, and R. J. O’Neil. 2004. A glycines biology in North America. Ann. Entomol. Soc. Am. 97: 204-208.

Rice, M. E., M. O'Neal, and P. Pedersen. 2005. Soybean aphids in Iowa. Iowa State University Extension, Ames, IA. (http:/ / www.ent.iastate.edu/ soybeanaphid/files / Aphids.SP247 0.pdf).

Ritchie, S. W., J. J. Hanway, H. E. Thompson, and G. O. Benson. 1995. How a soybean plant develops (J. C. Herman [ed.]), Iowa State University of Science and Technology Cooperative Extension Service, Ames, IA.

Rutledge, C. E., and R. J. O’Neil. 2006. Soybean plant stage and population growth of soybean aphid. J. Econ. Entomol. 99: 60-66.

Rutledge, C. E., R. J. O'Neil, T. B. Fox, and D. A. Landis. 2004. Soybean aphid predators and their use in integrated pest management. Ann. Entomol. Soc. Am. 97: $240-248$.

SAS Institute. 2002. PROC user's manual, version 9.1. SAS Institute, Cary, NC.

[EPA] U.S. Environmental Protection Agency. 1991. Memorandum from the Office of Pesticides and Toxic Sub- 
stances to Office of Pesticide Programs Division Director, Washington, DC; 5-6 (as summarized in EXTOXNET PIP Malathion. http:// extoxnet.orst.edu/pips/malathio. htm).

van den Berg, H. D. Ankasah, A. Muhammad, R. Rusli, H. A. Widayanto, H. B. Wirasto, and I. Yully. 1997. Evaluating the role of predation in population fluctuations of the soybean aphid in farmer's fields in Indonesia. J. Appl. Ecol. 34: 971-984.
Venette, R. C., and D. W. Ragsdale. 2004. Assessing the invasion by soybean aphid (Homoptera: Aphididae) where will it end? Ann. Entomol. Soc. Am. 97: 219-226.

Yue, Z. D., and J. F. Hao. 1990. Monitoring and control threshold of the soybean aphid in the Jilin province. Monit. Pred. Dis. Pests 3: 28-30.

Received 7 February 2007; accepted 16 April 2007. 